\title{
Perfusion-Based Recellularization of Rat Livers with Islets of Langerhans
}

\author{
Peter Demko ${ }^{1}$ Karl H. Hillebrandtt ${ }^{1,3} \cdot$ Hendrik Napierala $^{1} \cdot$ Nils Haep $^{1} \cdot$ Peter Tang ${ }^{1} \cdot$ Joseph M. G. V. Gassner ${ }^{1,3}$. \\ Martin Kluge ${ }^{1} \cdot$ Hannah Everwien ${ }^{1} \cdot$ Dietrich Polenz ${ }^{1} \cdot$ Anja Reutzel-Selke ${ }^{1} \cdot$ Nathanael Raschzok $^{1,3}$. \\ Johann Pratschke ${ }^{1} \cdot$ Igor M. Sauer $^{1} \cdot$ Benjamin Struecker ${ }^{1,2,3} \cdot$ Eva M. Dobrindt ${ }^{1,4}$ (D)
}

Received: 1 January 2022 / Accepted: 14 February 2022 / Published online: 8 March 2022

(c) The Author(s) 2022

\begin{abstract}
Purpose Artificial organs might serve as alternative solutions for whole organ transplantation. Decellularization of a liver provides a non-immunogenic matrix with the advantage of three afferent systems, the portal vein, the hepatic artery and the bile duct. This study aims to evaluate the recellularization of rat livers with islets of Langerhans via the bile duct and the portal vein for the comparison of different perfusion routes.

Methods Rat livers were decellularized in a pressure-controlled perfusion manner and repopulated with intact isolated islets of Langerhans via either the portal vein or the bile duct.

Results Repopulation via the portal vein showed islet clusters stuck within the vascular system demonstrated by ellipsoid borders of thick reticular tissue around the islet cluster in Azan staining. After recellularization via the bile duct, islets were distributed close to the vessels within the parenchymal space and without a surrounding reticular layer. Large clusters of islets had a diameter of up to $1000 \mu \mathrm{m}$ without clear shapes.

Conclusion We demonstrated the bile duct to be superior to the portal vein for repopulation of a decellularized rat liver with islets of Langerhans. This technique may serve as a bioengineering platform to generate an implantable and functional endocrine neo-pancreas and provide scaffolds with the anatomic benefit of three afferent systems to facilitate co-population of cells.
\end{abstract}

Keywords Tissue engineering $\cdot$ Islets of Langerhans $\cdot$ Neo-organ $\cdot$ Extracellular matrix $\cdot$ Decellularization · Recellularization

Benjamin Struecker and Eva M. Dobrindt have contributed equally to the presented work.

Eva M. Dobrindt

eva-maria.dobrindt@charite.de

1 Department of Surgery, Experimental Surgery, CharitéUniversitätsmedizin Berlin, 10117 Berlin, Germany

2 Department of General, Visceral and Transplant Surgery, Universitätsklinikum Münster, 48149 Munster, Germany

3 BIH-Charité (Junior) Clinician Scientist Program, 10178 Berlin, Germany

4 Department of Surgery, CCMICVK, CharitéUniversitätsmedizin Berlin, Augustenburger Platz 1, 13353 Berlin, Germany

\section{Introduction}

Diabetes mellitus type 1 had a prevalence of 1.93 per 1000 in the US 2009 and requires life-long treatment [1]. Exogenous insulin replacement helps to regulate blood glucose levels in order to prevent vascular, renal and neurological complications. However, sufficient metabolic regulation cannot be reached in some patients, and pancreas or islet transplantation may be indicated for further therapy [1-3].

Pancreas transplantation is an established procedure and predominant to islet transplantation, but bares the risk for major complications, e.g. acute rejection, post-transplantation pancreatitis and severe infections, leading to graft loss in approximately $10 \%$ of patients $[4,5]$. In contrast, islet transplantation appears to be less invasive and safer [4]. Nevertheless, metabolic function after islet transplantation is negatively affected by hypoxia, partial portal vein 
thrombosis and the instant blood-mediated inflammatory reaction due to the intraportal access and the unphysiological site of engraftment [6-9].

Modern tissue engineering techniques like the repopulation of decellularized organs and bio-fabrication of so-called neo-organs might provide a new perspective, while avoiding the above-mentioned issues [3, 10]. The decellularization process almost completely removes the antigenic material from the tissue, leaving the most likely non-immunogenic extracellular matrix (ECM) of the organ [3]. The ECM may serve as a biochemically and geometrically perfect scaffold, retaining basic components, such as proteins, growth factors. The complex branching architecture and basal lamina of the former vascular system is also preserved after decellularization $[11,12]$. This decellularized organ matrix can be recellularized with any kind of cell population [12-14]. This technique enables the engineering of a solely endocrine neopancreas without exocrine cells, which cause post-transplant pancreatitis [3].

Former investigations of our group established the recellularization of a decellularized rat pancreas with islets of Langerhans [3]. However, islets are large cell clusters. The application via the portal vein led to insufficient distribution as the islet clusters mostly colonized the vascular lumen [3, 15]. to the islets did not cross the intact basal membrane ot the vascular protein network into the decellularized parenchymal space $[3,16]$. In contrast, former studies described the recellularization of decellularized liver matrix with islets of Langerhans or islets-like clusters via the portal vein $[15,17]$. The micro-structure of the liver provides the great advantage of three afferent systems: the portal vein, the arterial system as well as the biliary tract, which is not surrounded by a endothelial and basal membrane boundary at the terminal branches and might, thus serve as an alternative access to inner parenchymal space. In addition, the 3D matrix and texture of the decellularized rat pancreas was soft and fragile [3]. Therefore, a decellularized rat liver might serve as an alternative scaffold, as its decellularization process is well-described [16-31] anda first proof-of-concept for engrafting islets of Langerhans in a decellularized rat liver via the bile duct has been shown in our group [32].

To our knowledge there is no existing data about the comparison of the different afferent application ways of the liver. The objective of this investigation was to compare the two different cell application routes, the portal vein and the bile duct, to recellularize a previously decellularized rat liver with isolated islets of Langerhans in terms of cell distribution and feasibility (Fig. 1).

Secondly, in order to preserve as much of the ECM as possible, we tried to optimize our established decellularization protocol by controlling the perfusion pressure during decellularization. Our group was able to establish a protocol for rat liver decellularization via the hepatic artery under

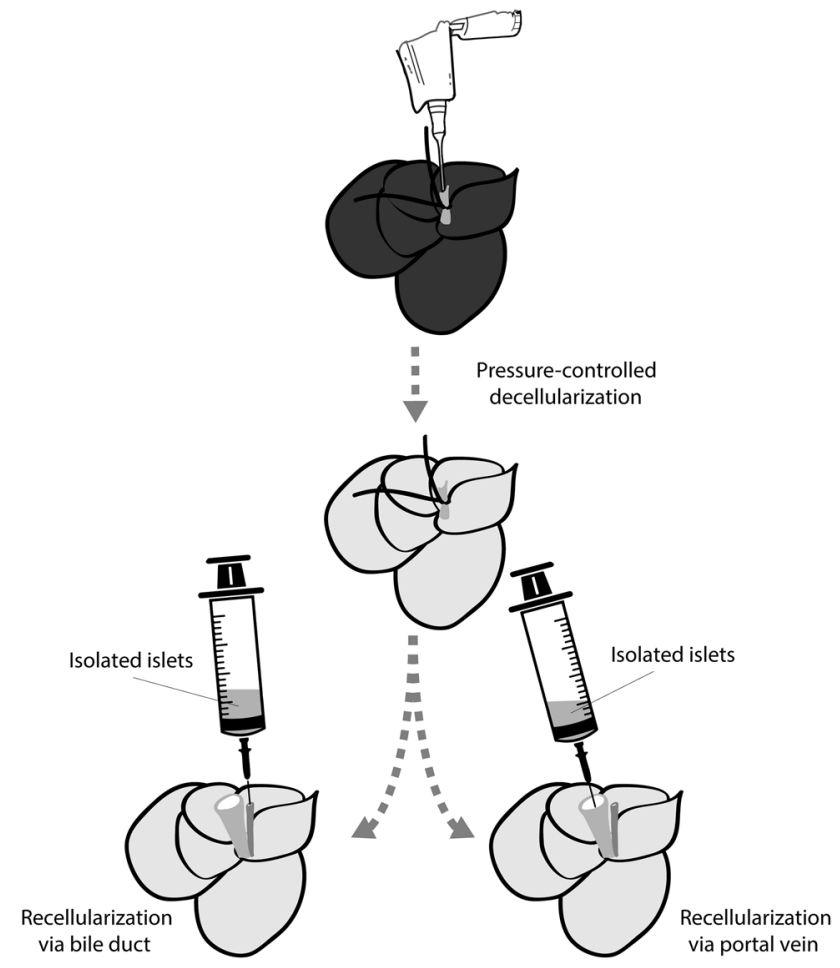

Fig. 1 Schematic display of the experimental setup for the recellularization process. Recellularization was performed via bile duct (left) or portal vein (right). The infusion was performed by a syringe either controlled by an infusion pump or manually

oscillating pressure conditions [22, 23]. As vascular resistance changes during the decellularization process, the flow rate increases until the end of the decellularization causing damage to the basal membrane [33-35]. This damage can be reduced by low or graduated flow rates in a pressurecontrolled approach $[33,36]$.

\section{Materials and Methods}

Twelve male and female rats (Lewis rats expressing green fluorescent protein and female Wistar rats) weighing between 300 and $450 \mathrm{~g}$ were used for the decellularization evaluation experiments. Six decellularization experiments were accomplished by using a pressure-controlled setup, three according to the protocol of Struecker et al., and three untreated rats served as a control [22, 23]. Twelve male Wistar rats (ENVIGO) served as liver graft donors for the repopulation experiments. Three animals were assigned to each of four groups: (I) Islet infusion through the portal vein (PV) using an infusion pump; (II) islet infusion via the bile duct (BD) using an infusion pump; (III) manual islet infusion via the PV using a syringe; (IV) manual islet infusion via the BD using a syringe (Fig. 1). Preliminary experiments had shown that arterial reperfusion was not 
feasible due to the hepatic artery's small lumen. Since islets of Langerhans are not single cells but cell clusters with a tendency to form even larger clots, the artery clogged irreversibly and almost immediately. The islets for the described experiments were isolated from the pancreases of 72 female Wistar ex-breeders.

\subsection{Surgical Procedure of Rat Liver Explantation}

For rat liver explantation we modified the protocol published by Struecker et al. [22, 23]: Rats were anaesthetized by inhalation of isoflurane (5\% for narcosis induction and $2 \%$ for maintenance) and a subcutanaeous injection of ketamine $(10 \mathrm{mg} / \mathrm{kg})$, medetomidine hydrochloride $(0.1 \mathrm{mg} / \mathrm{kg})$ and metamizol $(100 \mathrm{mg} / \mathrm{kg})$. The celiac trunk was prepared to the aortic origin and the superior pancreaticoduodenal, lienopancreatic and gastricolienal arteries as well as the prepyloric vein were ligated and transected. For better access to the right suprarenal vessels, the renal vein and artery were ligated, transected, and the right kidney removed. The BD was incised, and cannulated. $1 \mathrm{ml}$ of saline with 500 I.U. of heparin was infused into the infrahepatic vena cava inferior and the animal finalized by dissection of the right atrium. The PV was incised at the level of the lower mesenteric vein and cannulated using an $18 \mathrm{G}$ infusion catheter. The coeliac trunk was excised with an aortic patch to cannulate the hepatic artery with a plastic tube prefilled with Ringer solution (Polythan Tubing, $0.58 \mathrm{~mm}$ i.d.; $0.96 \mathrm{~mm}$ i.d.; Smith Portex Ltd., Kent, UK) and connected to an $18 \mathrm{G}$ infusion catheter. The infrahepatic vena cava inferior was cannulated using a $12 \mathrm{G}$ catheter. The liver was perfused via the portal vein with $20 \mathrm{ml}$ Ringer solution for complete exsanguination. After ligation and dissection of the vena cava between liver and diaphragm, the liver was removed and stored in $100 \mathrm{ml}$ Ringer solution and frozen at $-80^{\circ} \mathrm{C}$ until further use.

\subsection{Perfusion Decellularization}

Before starting each experiment, the liver was left at $+4{ }^{\circ} \mathrm{C}$ to thaw for $24 \mathrm{~h}$. If the liver was designated for recellularization, the median and the left lateral lobe were ligated in order to reduce the volume of the matrix (recellularizing just the caudal and right lateral lobe). The cannulated liver's artery was connected to a pressure-controlled perfusion system, which was set to $100 \mathrm{mmHg}$, and placed into a closed bioreactor with oscillating pressure conditions as published before [31]. After an initial perfusion with phosphate buffered saline (PBS; Biochrom, Berlin, Germany) for 45 min the liver was perfused with $1 \%$ sodium dodecyl sulfate (SDS; Carl Roth, Karlsruhe, Germany) for $12 \mathrm{~h}$. This was followed by $45 \mathrm{~min}$ of perfusion with $1 \%$ Triton X (Carl Roth, Karlsruhe, Germany) and finally $12 \mathrm{~h}$ of flow-controlled perfusion with PBS supplemented with Penicillin-Streptomycin (Biochrom, Berlin, Germany) at $0.7 \mathrm{ml} / \mathrm{min}$. The decellularized livers were either prepared for further analysis or used as grafts for repopulation experiments immediately.

Livers that were exclusively used for comparative decellularization were thawed at $+4{ }^{\circ} \mathrm{C}$ for $24 \mathrm{~h}$ and placed into a closed bioreactor with oscillating pressure conditions following the protocol of Struecker et al. [23]. The arterial cannula was connected to a flow-controlled perfusion system set to $5 \mathrm{ml} / \mathrm{min}$. The livers were perfused with $1 \%$ Triton $\mathrm{X}$ for $90 \mathrm{~min}$ and subsequently with $1 \%$ SDS solution for another $90 \mathrm{~min}$. After the decellularization process, the livers were washed for $12 \mathrm{~h}$ with PBS supplemented with Penicillin-Streptomycin (Biochrom, Berlin, Germany) at $0.7 \mathrm{ml} /$ min. Following this samples were immediately prepared for further analysis.

\subsection{Islet Isolation}

Islet isolation was performed according to the protocol by Schubert et al. [37]. The animals were sacrificed by exsanguination and $\mathrm{a}+4{ }^{\circ} \mathrm{C}$ enzyme solution containing Collagenase from Clostridium histolyticum (Sigma-Aldrich Darmstadt, Germany) and DNase I (F. Hoffmann-La Roche, Basel, Switzerland) was infused through the common bile duct into the pancreatic tissue. The pancreases were removed and stored on ice under sterile conditions until further preparation. Afterwards the pancreases were digested at $37{ }^{\circ} \mathrm{C}$ for $15 \mathrm{~min}$. The cell suspension was washed, and islet purification was performed using a discontinuous Ficoll gradient (Sigma-Aldrich/Merck, Darmstadt, Germany). The obtained islets were cultured in RPMI 1640 medium (Gibco ${ }^{\circledR}$ Thermo Fisher Scientific, Darmstadt, Germany) with a Glucose concentration of $5.5 \mathrm{mM}$ and supplemented with 10\% FCS (Biochrom, Berlin, Germany). The number of islets was determined using dithizone staining (SigmaAldrich/Merck, Darmstadt, Germany) and then immediately used for recellularization experiments.

\subsection{Recellularization}

Depending on the route of cell infusion, which was either the PV or the BD, all the other outflows were ligated. The organ matrix was gently expanded by infusing $5-15 \mathrm{ml}$ of PBS (Biochrom, Berlin, Germany) using a $20 \mathrm{ml}$ syringe. $10,000-20,000$ islets in $10 \mathrm{ml}$ of medium were infused per organ either manually in about $30 \mathrm{~s}$ or using an infusion pump with a perfusion rate of $99 \mathrm{ml} / \mathrm{min}$. Another $3 \mathrm{ml}$ of PBS (Biochrom, Berlin, Germany) were infused in order to 
clear the infusion cannula. The livers were left for $15 \mathrm{~min}$ to deflate and then prepared for histological analysis.

\subsection{Main Measures}

Decellularized livers were stained using Hematoxylin (AppliChem, Darmstadt, Germany) Eosin (Morphisto, Frankfurt am Main, Germany), Sirius Red (Sigma-Aldrich, Hamburg, Germany) and Alcian Blue (Morphisto, Frankfurt am Main, Germany). For immunohistochemical stainings primary antibodies against collagen IV (Abcam, Cambridge, United Kingdom, Cat: ab6586), laminin (Abcam, Cambridge, United Kingdom, Cat: ab11575) and fibronectin (Abcam, Cambridge, United Kingdom, Cat: ab23751) were used.

The recellularized liver matrices were stained by Azan (Morphisto, Frankfurt am Main, Germany), Hematoxylin (AppliChem, Darmstadt, Germany) and Eosin (Morphisto, Frankfurt am Main, Germany).

DNA content was measured using DNeasy Blood and Tissue Kit (Quiagen, Hilden, Germany) according to the manufacturer's instructions. Photometric measurement was performed using a NanoDrop ${ }^{\mathrm{TM}} 2000 \mathrm{c}$ spectrophotometer (Thermo Fisher Scientific, Waltham, Massachusetts, USA). Soluble gylcosaminoclycan (sGAG) and SDS contents were measured using dimethylene blue staining and quantification in a NanoDrop ${ }^{\mathrm{TM}}$ 2000c spectrophotometer (Thermo Fisher Scientific, Waltham, Massachusetts, USA) according to the method described by Farndale et al. and Hayashi et al. [38, 39].

Statistical analysis was performed by IBM SPSS Statistic Software (Version 22, Armonk, New York, USA). Significances were calculated by Kruskal-Wallis-test and OneWay-Anova. Significance level was $\mathrm{p}<0.05$. Histological images were taken by using ZEN microscope 2.3 pro (Carl Zeiss Microscopy Deutschland GmbH, Oberkochen, Germany). Images were created by Adobe Illustrator (Version
22.0 for macOS, Adobe, San José, CA, USA) and graphs by GraphPad Prism 7 Software (Statcon; La Jolla, CA, USA).

\section{Results}

\subsection{Biochemical Evaluation of the Decellularization Process}

At the end of the decellularization procedure, both groups showed a decline in DNA content compared to the control group [flow-controlled: $2.5 \mu \mathrm{g} / \mathrm{mg}(0.7-4.2)$; pressurecontrolled: $4.0 \mu \mathrm{g} / \mathrm{mg}(0.6-57.7)$; control: $124.0 \mu \mathrm{g} / \mathrm{mg}$ (107.8-188.5), Fig. 2]. There was no statistically significant difference between the two groups $(p=0.277)$. The sGAG content in both groups was higher than in the control group [flow-controlled: $17.3 \mu \mathrm{g} / \mathrm{mg}(11.2-25.2)$; pressure-controlled: $13.4 \mu \mathrm{g} / \mathrm{mg}$ (6.3-34.4); control: $3.3 \mu \mathrm{g} / \mathrm{mg}$ (2.9-4.8), Fig. 2], again no significant difference between the two decellularized groups could be found ( $p>0.999$ ). The total SDS content showed no statistically significant difference between the two groups [flow-controlled: $0.4 \mu \mathrm{g} /$ $\mathrm{mg}(0.2-1.1)$; pressure-controlled: $0.2 \mu \mathrm{g} / \mathrm{mg}(0.0-0.9)$; p $>0.999$, Fig. 2].

\subsection{Histological Evaluation of the Decellularization Process}

Hematoxylin and eosin staining revealed that in both groups the decellularization process left the liver matrix free of any residual cells while the ECM network appeared intact (Fig. 3A1-3). In both groups Sirius Red staining showed no residual parenchymal cells, which would have appeared yellow, as only red stained collagenous fibers were seen (Fig. 3B1-3). Alcian blue staining showed the presence of Glycosaminoglycans (blue) and absence of nuclei or
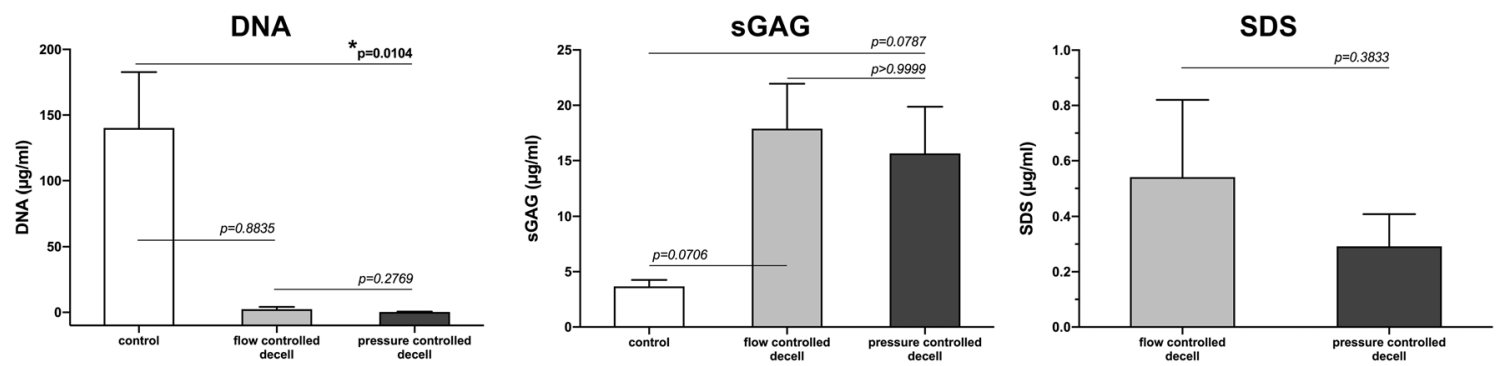

Fig. 2 Content of DNA, sGAG and SDS in $\mu \mathrm{g} / \mathrm{mg}$ after decellularization process for the three groups: native control, flow controlled decellularization and pressure controlled decellularization. There was a significantly different distribution between all three groups but not between flow controlled decellularization and pressure controlled decellularization for DNA $(n=6)$. There was a significantly different distribution between all three groups for sGAG but not between flow controlled decellularization and pressure controlled decellularization $(n=6)$. There was a significantly different distribution between SDS content of all three groups but not between flow controlled decellularization and pressure controlled decellularization $(n=6)$ 


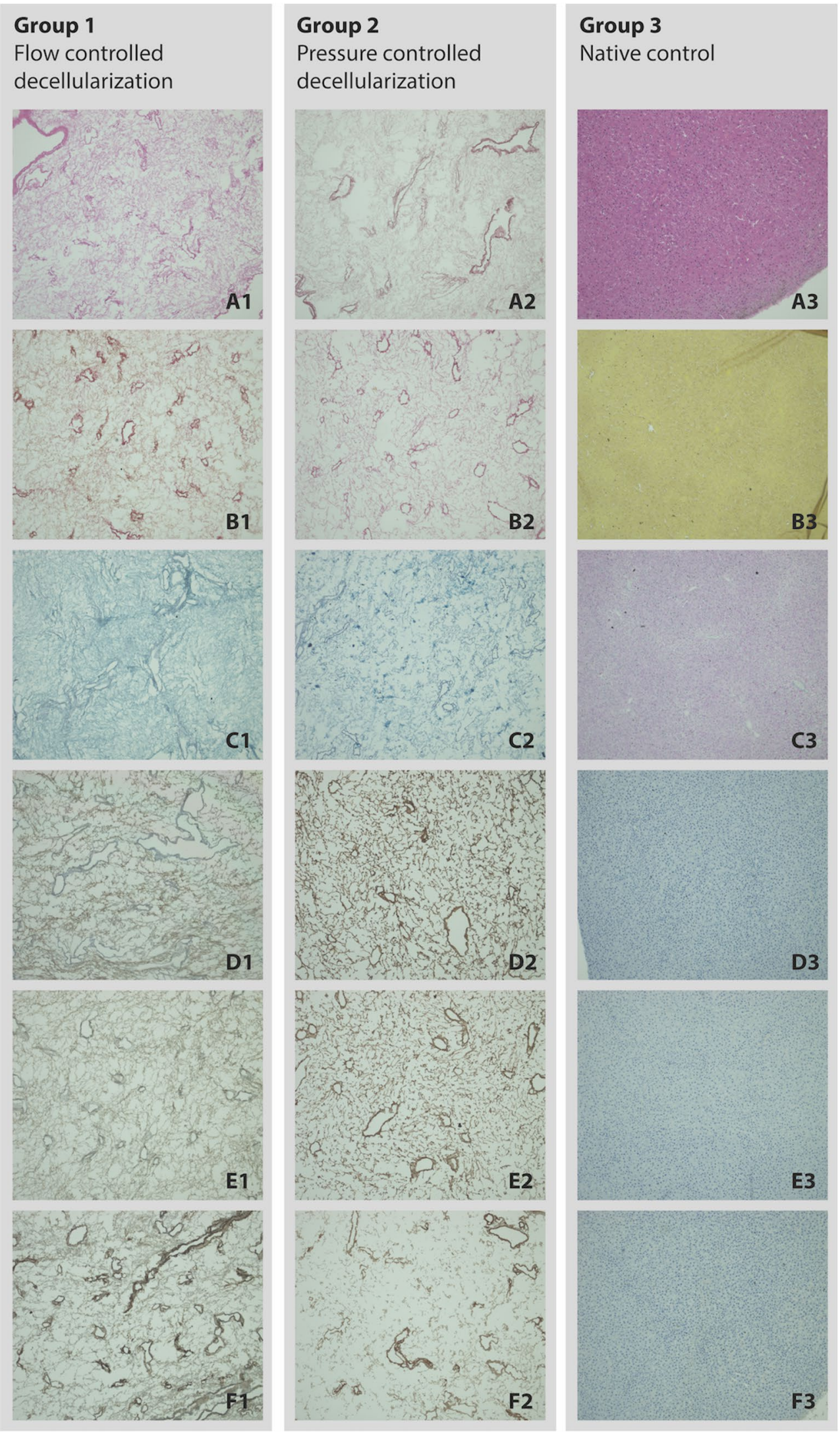

Fig. 3 Histopathological stainings: A-Hematoxylin and eosin, B — Sirius Red, C-Alcian Blue, D—Collagen IV, E-Fibronectin, F-Laminin. Group 1-flow controlled decellularization (1), group 2-pressure controlled decellularization (2), native control (3). $\mathrm{N}=6$. (Color figure online) 
cytoplasm (pink to red) in both groups (Fig. 3C1-3). Collagen IV, Fibronectin and Laminin could also be detected in both groups (Fig. 3D1-F3).

\subsection{Histological Evaluation of the Recellularized Grafts}

In all four groups, hematoxylin and eosin staining showed islets or islet clusters in the center and periphery of the repopulated liver lobes. In groups I and III (recellularization via portal vein), cells predominantly appeared in well-defined shapes with clear borderlines between cells and matrix (Fig. 4). These shapes were either elliptic or dendritic, thus reproducing the lumen of the portal vein's branches. No difference could be found between the methods of using a pump syringe and infusing the islets manually (Fig. 4). In groups II and IV (recellularization via bile duct), the hematoxylin and eosin stains did not show islets occurring in such well-defined shapes. Islets were scattered across the decellularized tissue, neighboring vascular branches. Large clusters of islets did occur, however, none of them had such clear borderlines as mentioned above. Since they did not appear to be enclosed by a basal membrane, some singular clusters reached sizes around $1000 \mu \mathrm{m}$. No difference could be shown between groups II and IV.

Azan staining showed islets in red and collagenous and reticular tissue in blue. The cell clusters in groups I and III were bordered by a thick layer of reticular tissue, which leads to the conclusion that the islets were largely caught within the venous system. Cell clusters in groups II and IV were not surrounded by such a layer. Smaller clusters predominantly appeared right next to such structures (Fig. 5).

\section{Discussion}

Donor shortage and postoperative complications after whole organ transplantation provoked the field of pancreatic tissue engineering. Engineering an artificial organ requires an
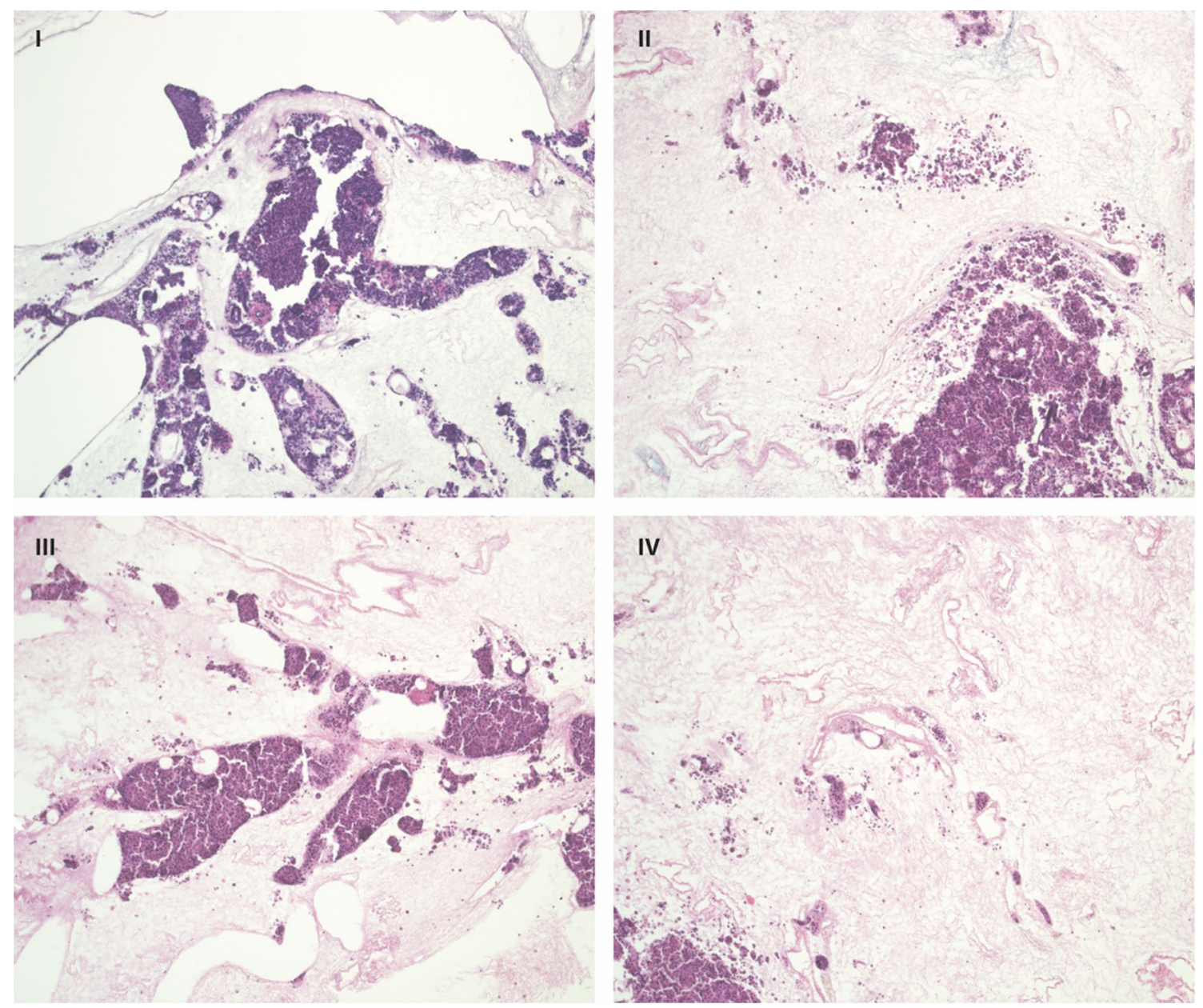

Fig. 4 Hematoxylin and eosin staining: I Islet infusion through the portal vein using an infusion pump; II Islet infusion via the bile duct using an infusion pump; III Manual Islet infusion via using a syringe; IV Manual islet infusion via using a syringe. $\mathrm{n}=6$ 

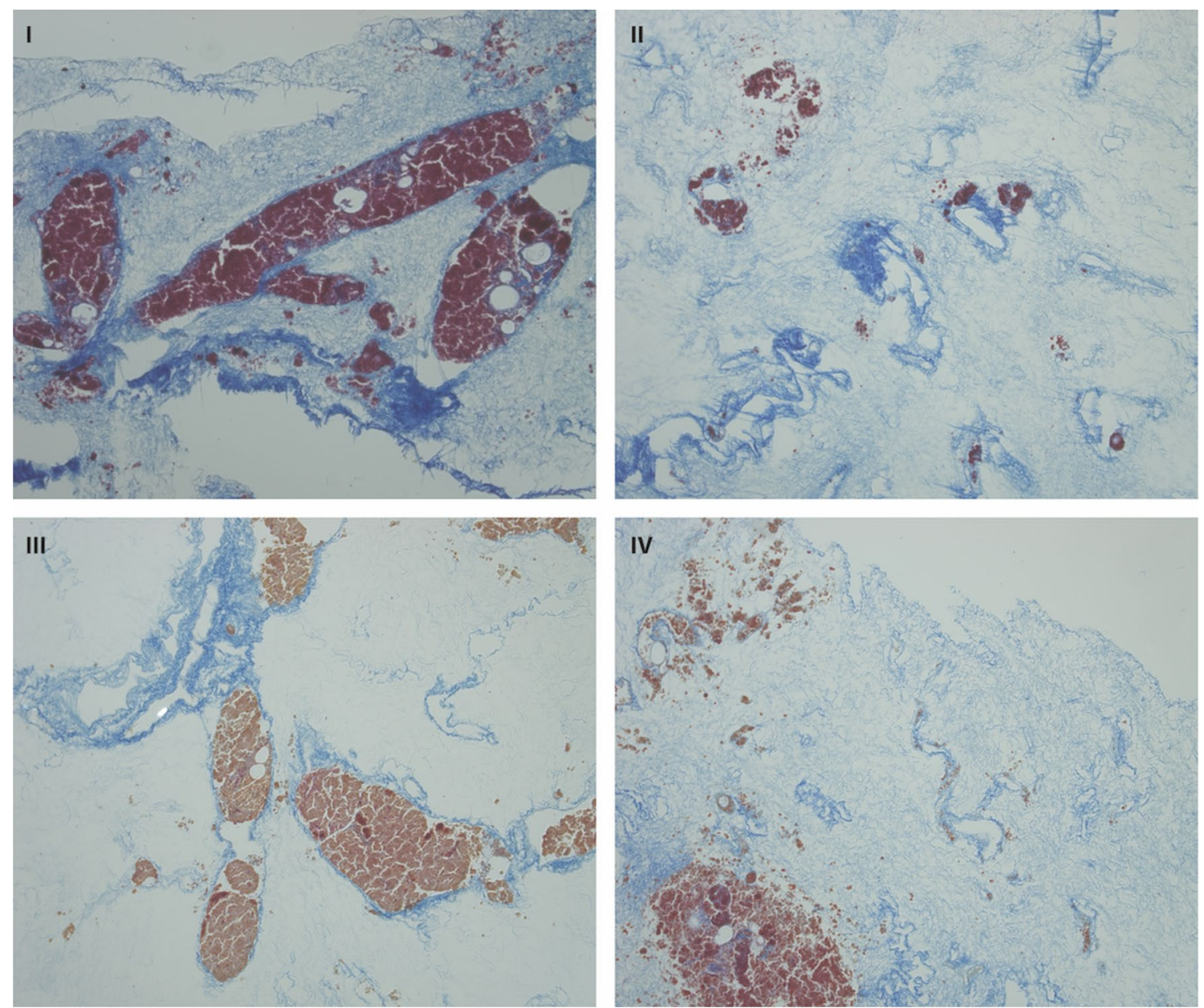

Fig. 5 Azan staining: I Islet infusion through the portal vein using an infusion pump; II Islet infusion via the bile duct using an infusion pump; III Manual Islet infusion via using a syringe; IV Manual islet infusion via using a syringe. $\mathrm{n}=6$

adequate cell source and a suitable matrix architecture to ensure survival of the cells, maturation of the organ and successful implantation. Many studies investigated synthetic scaffolds, especially, for islet transplantation to improve vascularization and oxygen supply [40]. However, polymers can cause unphysiological cell-biomaterial interactions and remain a critical approach [40]. In comparison, a decellularized organ matrix provides a more physiological environment and an immunogenically reduced, natural scaffold [23].

One part of this study was to advance our established protocol and preserve as much of the ECM as possible by controlling the perfusion pressure during decellularization. The previous described oscillating pressure is associated with an increasing flow rate until the end of the procedure injuring the basal membrane [33-35]. Low or graduated flow rates in a pressure-controlled approach might reduce this injury [33, 36]. Therefore, we attempted to optimize our established protocol by applying a constant pressure of $100 \mathrm{mmHg}$ during the perfusion process. Histopathological and biochemical evaluation showed comparable results of the previous and the pressure-controlled method with satisfying results concerning the decellularization of the matrix and no significant biochemical differences between both groups. We were unable to determine histopathological differences concerning the basal membrane by regarding laminin, fibronectin and collagen. However, damage to the basal membrane is hard to identify. As the decellularization was comparable in our studies, and the benefit of pressure-controlled perfusion has already been confirmed by others, we decided to use the pressure-controlled method for our recellularization experiments [36, 41].

The main objective of this investigation was to examine two different application routes of a decellularized rat liver for recellularization with islets of Langerhans: the portal vein and the bile duct. Former studies describe the usage of both afferent ways but without an existing scientific foundation [16, 17, 32]. Nevertheless, former investigations already showed an insufficient distribution of islets after recellularization via the portal vein, as the islets clustered within the vascular lumen $[3,36]$. We could confirm these findings and 
underline, that islets were unable to cross the basal membrane of the vessels. In contrast, the terminal branches of the bile duct are not surrounded by a boundary and recellularization via the bile duct showed a sufficient distribution. Islets settled next to the arterial and portal system according to the architectonic structure of the hepatic anatomy but stayed within the decellularized parenchymal space. In addition, the close neighborhood to the vascular system might be an advantage of the bile duct as an application way to perform re-endothelization. In the end, the re-colonization of the neoorgan with endothelial cells or other co-populations will be crucial for a successful in vivo implantation without thrombosis [28, 30, 33, 34, 36, 40-45].

However, the entire decellularized matrices could not be repopulated as the number of islets in relation to the size of the matrix was too low. To provide an adequate number of islets, numerous animals would have to be sacrificed. This discrepancy might be a problem of the small animal model and will maybe be solved in large animal models or even human transplantation. If the homogenous recellularization of a decellularized liver matrix can be maintained technically, the cell source in case of for example xeno- or even human auto-transplantation might enable a larger number of islets per each single isolation.

\section{Conclusion}

We demonstrated the benefit of the bile duct instead of the portal vein as a repopulation route for a decellularized rat liver. The parenchymal space of a decellularized liver can be engrafted with islets via the bile duct, despite their great size. Secondly, the attempt to optimize our established protocol of Streucker et al. by applying a constant pressure of $100 \mathrm{mmHg}$ during the perfusion process did show satisfying results concerning the decellularization of the rat liver. There were comparable results without significant differences between the previous and the pressure-controlled protocol.

The next steps towards a neo-pancreas will be the further evaluation of survival and function of the islets in vitro as well as gaining sufficient re-endothelialization in order to initiate in vivo-i.e. implantation-experiments.

Author Contributions Conceptualization: BS, EMT; Methodology: PT, DP; Formal analysis and investigation: KHH, HN, NH, MK, HE; Writing - original draft preparation: EMT, PD. Writing—review and editing: JP, NR, JMGVG. AR-S, BS; Supervision: IMS, AR-S.

Funding Open Access funding enabled and organized by Projekt DEAL. Benjamin Struecker and Nathanael Raschzock were, Karl Hillebrandt and Joseph Gassner are participants in the BIH-Charité
Clinician Scientist Program funded by the Charité-Universitätsmedizin Berlin and the Berlin Institute of Health.

\section{Declarations}

Conflict of interest The authors have no relevant financial or non-financial interests to disclose.

Ethical Approval This study was performed in line with the principles of the Declaration of Helsinki. All animal experiments were performed according to local laws and approved by the State Office of Health and Social Affairs (LAGeSo, Berlin, Germany). Animal experiments conform to internationally accepted standards and have been approved by the appropriate review body (LaGeSo, Berlin, Germany; Reg. No. T0139/13, O0262/13, O264/13 and o0365/11).

Open Access This article is licensed under a Creative Commons Attribution 4.0 International License, which permits use, sharing, adaptation, distribution and reproduction in any medium or format, as long as you give appropriate credit to the original author(s) and the source, provide a link to the Creative Commons licence, and indicate if changes were made. The images or other third party material in this article are included in the article's Creative Commons licence, unless indicated otherwise in a credit line to the material. If material is not included in the article's Creative Commons licence and your intended use is not permitted by statutory regulation or exceeds the permitted use, you will need to obtain permission directly from the copyright holder. To view a copy of this licence, visit http://creativecommons.org/licenses/by/4.0/.

\section{References}

1. Dabelea, D., Mayer-Davis, E. J., Saydah, S., Imperatore, G., Linder, B., Divers, J., Bell, R., Badaru, A., Talton, J. W., Crume, T., Liese, A. D., Merchant, A. T., Lawrence, J. M., Reynolds, K., Dolan, L., Liu, L. L., Hamman, R. F., SEARCH for Diabetes in Youth Study. (2014). Prevalence of type 1 and type 2 diabetes among children and adolescents from 2001 to 2009. JAMA, 311, 1778-1786. https://doi.org/10.1001/jama.2014.3201

2. Atkinson, M. A., Eisenbarth, G. S., \& Michels, A. W. (2014). Type 1 diabetes. The Lancet, 383, 69.

3. Napierala, H., Hillebrandt, K. H., Haep, N., Tang, P., Tintemann, M., Gassner, J., Noesser, M., Everwien, H., Seiffert, N., Kluge, M., Teegen, E., Polenz, D., Lippert, S., Geisel, D., Reutzel Selke, A., Raschzok, N., Andreou, A., Pratschke, J., Sauer, I. M., \& Struecker, B. (2017). Engineering an endocrine Neo-Pancreas by repopulation of a decellularized rat pancreas with islets of Langerhans. Scientific Reports, 2(7), 41777. https://doi.org/10. 1038/srep41777

4. Ludwig, B., Ludwig, S., Steffen, A., Saeger, H. D., \& Bornstein, S. R. (2019). Islet versus pancreas transplantation in type 1 diabetes: Competitive or complementary? Current Diabetes Reports, 10, 506-511. https://doi.org/10.1007/s11892-010-0146-y

5. Barton, F. B., Rickels, M. R., Alejandro, R., Hering, B. J., Wease, S., Naziruddin, B., Oberholzer, J., Odorico, J. S., Garfinkel, M. R., Levy, M., Pattou, F., Berney, T., Secchi, A., Messinger, S., Senior, P. A., Maffi, P., Posselt, A., Stock, P. G., Kaufman, D. B., \& Shapiro, A. M. (2012). Improvement in outcomes of clinical islet transplantation: 1999-2010. Diabetes Care, 35, 1436-1445. https://doi.org/10.2337/dc12-0063

6. Olsson, R., Olerud, J., Pettersson, U., \& Carlsson, P. O. (2011). Increased numbers of low-oxygenated pancreatic islets after 
intraportal islet transplantation. Diabetes, 60, 2350-2353. https:// doi.org/10.2337/db09-0490

7. Kawahara, T., Kin, T., Kashkoush, S., Gala-Lopez, B., Bigam, D. L., Kneteman, N. M., Koh, A., Senior, P. A., \& Shapiro, A. M. (2011). Portal vein thrombosis is a potentially preventable complication in clinical islet transplantation. American Journal of Transplantation, 11, 2700-2707. https://doi.org/10.1111/j.16006143.2011.03717.x

8. Kawahara, T., Kin, T., \& Shapiro, A. M. (2012). A comparison of islet autotransplantation with allotransplantation and factors elevating acute portal pressure in clinical islet transplantation. Journal of Hepato-Biliary-Pancreatic Sciences, 19, 281-288. https://doi.org/10.1007/s00534-011-0441-2

9. Naziruddin, B., Iwahashi, S., Kanak, M. A., Takita, M., Itoh, T., \& Levy, M. F. (2014). Evidence for instant blood-mediated inflammatory reaction in clinical autologous islet transplantation. American Journal of Transplantation, 14, 428-437. https://doi. org/10.1111/ajt.12558

10. Struecker, B., Raschzok, N., \& Sauer, I. M. (2014). Liver support strategies: cutting-edge technologies. Nature Reviews Gastroenterology \& Hepatology, 11, 166-176. https://doi.org/10.1038/ nrgastro.2013.204

11. Wang, Y., Cui, C. B., Yamauchi, M., Miguez, P., Roach, M., Malavarca, R., Costello, M. J., Cardinale, V., Wauthier, E., Barbier, C., Gerber, D. A., Alvaro, D., \& Reid, L. M. (2011). Lineage restriction of human hepatic stem cells to mature fates is made efficient by tissue-specific biomatrix scaffolds. Hepatology, 53, 293-305. https://doi.org/10.1002/hep. 24012

12. Orlando, G., Farney, A. C., Iskandar, S. S., Mirmalek-Sani, S. H., Sullivan, D. C., Moran, E., AbouShwareb, T., De Coppi, P., Wood, K. J., Stratta, R. J., Atala, A., Yoo, J. J., \& Soker, S. (2012). Production and implantation of renal extracellular matrix scaffolds from porcine kidneys as a platform for renal bioengineering investigations. Annals of Surgery, 256, 363-370. https://doi.org/ 10.1097/SLA.0b013e31825a02ab

13. Song, J. J., \& Ott, H. C. (2011). Organ engineering based on decellularized matrix scaffolds. Trends in Molecular Medicine, 17, 424-432. https://doi.org/10.1016/j.molmed.2011.03.005

14. Sullivan, D. C., Mirmalek-Sani, S. H., Deegan, D. B., Baptista, P. M., Aboushwareb, T., Atala, A., \& Yoo, J. J. (2012). Decellularization methods of porcine kidneys for whole organ engineering using a high-throughput system. Biomaterials, 33, 7756-7764. https://doi.org/10.1016/j.biomaterials.2012.07.023

15. Xu, T., Zhu, M., Guo, Y., Wu, D., Huang, Y., Fan, X., Zhu, S., Lin, C., Li, X., Lu, J., Zhu, H., Zhou, P., Lu, Y., \& Wang, Z. (2015). Three-dimensional culture of mouse pancreatic islet on a liverderived perfusion-decellularized bioscaffold for potential clinical application. Journal of Biomaterials Applications, 30, 379-387. https://doi.org/10.1177/0885328215587610

16. von Mach, M. A., Schlosser, J., Weiland, M., Feilen, P. J., Ringel, M., Hengstler, J. G., Weilemann, L. S., Beyer, J., Kann, P., \& Schneider, S. (2003). Size of pancreatic islets of Langerhans: A key parameter for viability after cryopreservation. Acta Diabetologica, 40, 123-129. https://doi.org/10.1007/s00592-003-0100-4

17. Zhou, P., Guo, Y., Huang, Y., Zhu, M., Fan, X., Wang, L., Wang, Y., Zhu, S., Xu, T., Wu, D., Lu, Y., \& Wang, Z. (2016). The dynamic three-dimensional culture of islet-like clusters in decellularized liver scaffolds. Cell and Tissue Research, 365, 157-171. https://doi.org/10.1007/s00441-015-2356-8

18. Uygun, B. E., Soto-Gutierrez, A., Yagi, H., Izamis, M. L., Guzzardi, M. A., Shulman, C., Milwid, J., Kobayashi, N., Tilles, A., Berthiaume, F., Hertl, M., Nahmias, Y., Yarmush, M. L., \& Uygun, K. (2010). Organ reengineering through development of a transplantable recellularized liver graft using decellularized liver matrix. Nature Medicine, 16, 814-820. https://doi.org/10.1038/ nm. 2170
19. Shirakigawa, N., Ijima, H., \& Takei, T. (2012). Decellularized liver as a practical scaffold with a vascular network template for liver tissue engineering. Journal of Bioscience and Bioengineering, 114, 546-551. https://doi.org/10.1016/j.jbiosc.2012.05.022

20. Shupe, T., Williams, M., Brown, A., Willenberg, B., \& Petersen, B. E. (2010). Method for the decellularization of intact rat liver. Organogenesis, 6, 134-136. https://doi.org/10.4161/org.6.2.11546

21. Soto-Gutierrez, A., Wertheim, J. A., Ott, H. C., \& Gilbert, T. W. (2012). Perspectives on whole-organ assembly: moving toward transplantation on demand. Journal of Clinical Investigation, 122, 3817-3823. https://doi.org/10.1172/JCI61974

22. Struecker, B., Hillebrandt, K. H., Voitl, R., Butter, A., Schmuck, R. B., Reutzel-Selke, A., Andreou, A., Napierala, H., Raschzok, N., Pratschke, J., Sauer, I. M., \& Struecker, B. (2015). Porcine liver decellularization under oscillating pressure conditions: A technical refinement to improve the homogeneity of the decellularization process. Tissue Engineering Part C: Methods, 21, 303-313. https://doi.org/10.1089/ten.TEC.2014.0321

23. Struecker, B., Butter, A., Hillebrandt, K., Polenz, D., ReutzelSelke, A., Tang, P., Lippert, S., Leder, A., Rohn, S., Geisel, D., Denecke, T., Aliyev, K., Jöhrens, K., Raschzok, N., Neuhaus, P., Pratschke, J., \& Sauer, I. M. (2017). Improved rat liver decellularization by arterial perfusion under oscillating pressure conditions. Journal of Tissue Engineering and Regenerative Medicine, 11, 531-541. https://doi.org/10.1002/term.1948

24. Park, K. M., \& Woo, H. M. (2012). Systemic decellularization for multi-organ scaffolds in rats. Transplantation Proceedings, 44, 1151-1154. https://doi.org/10.1016/j.transproceed.2012.03.017

25. Ren, H., Shi, X., Tao, L., Xiao, J., Han, B., Zhang, Y., Yuan, X., \& Ding, Y. (2013). Evaluation of two decellularization methods in the development of a whole-organ decellularized rat liver scaffold. Liver International, 33, 448-458. https://doi.org/10.1111/ liv. 12088

26. Bao, J., Shi, Y., Sun, H., Yin, X., Yang, R., Li, L., Chen, X., \& $\mathrm{Bu}, \mathrm{H}$. (2011). Construction of a portal implantable functional tissue-engineered liver using perfusion-decellularized matrix and hepatocytes in rats. Cell Transplantation, 20, 753-766. https://doi. org/10.3727/096368910X536572

27. Baptista, P. M., Siddiqui, M. M., Lozier, G., Rodriguez, S. R., Atala, A., \& Soker, S. (2011). The use of whole organ decellularization for the generation of a vascularized liver organoid. Hepatology, 53, 604-617. https://doi.org/10.1002/hep.24067

28. Bosco, D., Orci, L., \& Meda, P. (1989). Homologous but not heterologous contact increases the insulin secretion of individual pancreatic B-cells. Experimental Cell Research, 184, 72-80. https://doi.org/10.1016/0014-4827(89)90365-0

29. De Kock, J., Ceelen, L., De Spiegelaere, W., Casteleyn, C., Claes, P., Vanhaecke, T., \& Rogiers, V. (2011). Simple and quick method for whole-liver decellularization: A novel in vitro three-dimensional bioengineering tool. Archives of Toxicology, 85, 607-612. https://doi.org/10.1007/s00204-011-0706-1

30. Butter, A., Aliyev, K., Hillebrandt, K. H., Raschzok, N., Kluge, M., Seiffert, N., Tang, P., Napierala, H., Muhamma, A. I., ReutzelSelke, A., Andreou, A., Pratschke, J., Sauer, I. M., \& Struecker, B. (2018). Evolution of graft morphology and function after recellularization of decellularized rat livers. Journal of Tissue Engineering and Regenerative Medicine, 12, e807-e816. https://doi.org/10. 1002/term.2383

31. Hillebrandt, K., Polenz, D., Butter, A., Tang, P., Reutzel-Selke, A., Andreou, A., Napierala, H., Raschzok, N., Pratschke, J., Sauer, I. M., \& Struecker, B. (2015). Procedure for decellularization of rat livers in an oscillating-pressure perfusion device. Journal of Visualized Experiments, 10, e53029. https://doi.org/10.3791/53029

32. Everwien, H., Keshi, E., Hillebrandt, K. H., Ludwig, B., Weinhart, M., Tang, P., Beierle, A. S., Napierala, H., Gassner, J. M., Seiffert, N., Moosburner, S., Geisel, D., Reutzel-Selke, A., Strücker, B., 
Pratschke, J., Haep, N., \& Sauer, I. M. (2020). Engineering an endothelialized, endocrine Neo-Pancreas: Evaluation of islet functionality in an ex vivo model. Acta Biomaterialia, 117, 213-225. https://doi.org/10.1016/j.actbio.2020.09.022

33. Crapo, P. M., Gilbert, T. W., \& Badylak, S. F. (2011). An overview of tissue and whole organ decellularization processes. Biomaterials, 32, 3233-3243. https://doi.org/10.1016/j.biomaterials.2011. 01.057

34. da Palma, R. K., Campillo, N., Uriarte, J. J., Oliveira, L. V., Navajas, D., \& Farré, R. (2015). Pressure- and flow-controlled media perfusion differently modify vascular mechanics in lung decellularization. Journal of the Mechanical Behavior of Biomedical Materials, 49, 69-79. https://doi.org/10.1016/j.jmbbm.2015.04. 024

35. Guyette, J. P., Gilpin, S. E., Charest, J. M., Tapias, L. F., Ren, X., \& Ott, H. C. (2014). Perfusion decellularization of whole organs. Nature Protocols, 9, 1451-1468. https://doi.org/10.1038/nprot. 2014.097

36. Ott, H. C., Matthiesen, T. S., Goh, S. K., Black, L. D., Kren, S. M., Netoff, T. I., \& Taylor, D. A. (2008). Perfusion-decellularized matrix: Using nature's platform to engineer a bioartificial heart. Nature Medicine, 14, 213-221. https://doi.org/10.1038/nm1684

37. Schubert, U., Schmid, J., Lehmann, S., Zhang, X. Y., Morawietz, H., Block, N. L., Kanczkowski, W., Schally, A. V., Bornstein, S. R., \& Ludwig, B. (2013). Transplantation of pancreatic islets to adrenal gland is promoted by agonists of growth-hormone-releasing hormone. Proceedings of the National Academy of Sciences, 5, 2288-2293. https://doi.org/10.1073/pnas.1221505110

38. Farndale, R. W., Buttle, D. J., \& Barrett, A. J. (1986). Improved quantitation and discrimination of sulphated glycosaminoglycans by use of dimethylmethylene blue. Biochimica et Biophysica (Acta)—BBA General Subjects, 883, 173-177. https://doi.org/10. 1016/0304-4165(86)90306-5
39. Hayashi, K. (1975). A rapid determination of sodium dodecyl sulfate with methylene blue. Analytical Biochemistry, 67, 503-506. https://doi.org/10.1016/0003-2697(75)90324-3

40. Smink, A. M., de Haan, B. J., Lakey, J. R. T., \& de Vos, P. (2018). Polymer scaffolds for pancreatic islet transplantation-Progress and challenges. American Journal of Transplantation, 18(9), 2113-2119. https://doi.org/10.1111/ajt.14942

41. Ott, H. C., Clippinger, B., Conrad, C., Schuetz, C., Pomerantseva, I., Ikonomou, L., Kotton, D., \& Vacanti, J. P. (2010). Regeneration and orthotopic transplantation of a bioartificial lung. Nature Medicine, 16(8), 927-933. https://doi.org/10.1038/nm.2193

42. Wang, Y., Cui, C. B., Yamauchi, M., Miguez, P., Roach, M., Malavarca, R., et al. (2011). Lineage restriction of human hepatic stem cells to mature fates is made efficient by tissue-specific biomatrix scaffolds. Hepatology, 53(1), 293-305. https://doi.org/10.1002/ hep. 24012

43. Jiang, B., Akgun, B., Lam, R. C., Ameer, G. A., \& Wertheim, J. A. (2015). A polymer-extracellular matrix composite with improved thromboresistance and recellularization properties. Acta Biomaterialia, 18, 50-58. https://doi.org/10.1016/j.actbio.2015.02.015

44. Ishida, N., Ishiyama, K., Saeki, Y., Tanaka, Y., \& Ohdan, H. (2019). Co-transplantation of pre-activated mesenchymal stem cells improves intraportal engraftment of islets by inhibiting liver natural killer cells in mice. American Journal of Transplantation, 19(10), 2732-2745. https://doi.org/10.1111/ajt.15347

45. Darmsteegt, E. L., Hassan, Z., Hewawasam, N. V., Sarnsamak, K., Jones, P. M., \& Hauge-Evans, A. C. (2019). A novel role for somatostatin in the survival of mouse pancreatic beta cells. Cellular Physiology and Biochemistry, 52(3), 486-502. https://doi. org/10.33594/000000035 